\title{
Insights into the effects of mechanism reduction on the performance of n-decane and its ability to act as a single-component surrogate for jet fuels
}

\author{
Mohsin Raza, Yebing Mao, Liang Yu, Xingcai Lu* \\ Key Laboratory for Power Machinery and Engineering of M. O. E., Shanghai Jiao Tong \\ University, Shanghai 200240, PR China
}

\section{Supplementary data}

Figure S1. Brute force sensitivity analysis conducted at $950 \mathrm{~K}$ and pressure of 50 bar

Figure S2. Brute force sensitivity analysis conducted at $1200 \mathrm{~K}$ and pressure of $10 \mathrm{bar}$

Figure S3. Mole fractions of species in a jet-stirred reactor (a) $\mathrm{nC}_{10} \mathrm{H}_{22}, \mathrm{O}_{2}$ at $700 \mathrm{ppm}$ of ndecane, the residence time of $0.07 \mathrm{~s}$ and a pressure of $1 \mathrm{~atm}(\mathrm{~b}) \mathrm{CO}_{2}, \mathrm{CH}_{4}$ (c) $\mathrm{CO}, \mathrm{C}_{2} \mathrm{H}_{4}$ at 1000 ppm of n-decane, the residence time of $0.5 \mathrm{~s}$ and a pressure of 10atm. Experimental data are taken from 10,40

Figure S4. Brute force sensitivity analysis based on the reaction classes observed in the oneeighth reduced mechanism at 10 bar and different temperature conditions.

Figure S5. Brute force sensitivity analysis based on the reaction classes observed in the detailed mechanism at 50 bar and different temperature conditions.

Figure S6. Comparison of n-decane ignition delays measured using current reduced mechanism and mechanism of Chang et al. ${ }^{18}$ and Qiu et al. ${ }^{50}$

Figure S7. Comparison of ignition delays of Jet A, Jet RP-3, and Jet S8 fuels measured with current reduced mechanism and mechanism of Chang et al. ${ }^{18}$ and Qiu et al. ${ }^{50}$ 


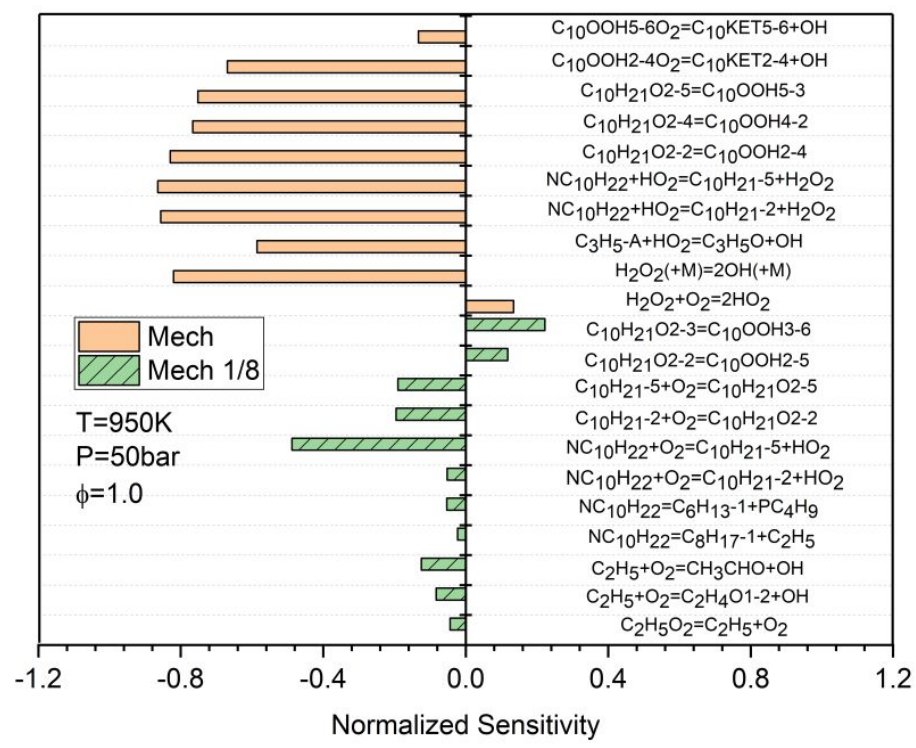

Figure S1. Brute force sensitivity analysis conducted at $950 \mathrm{~K}$ and pressure of $50 \mathrm{bar}$

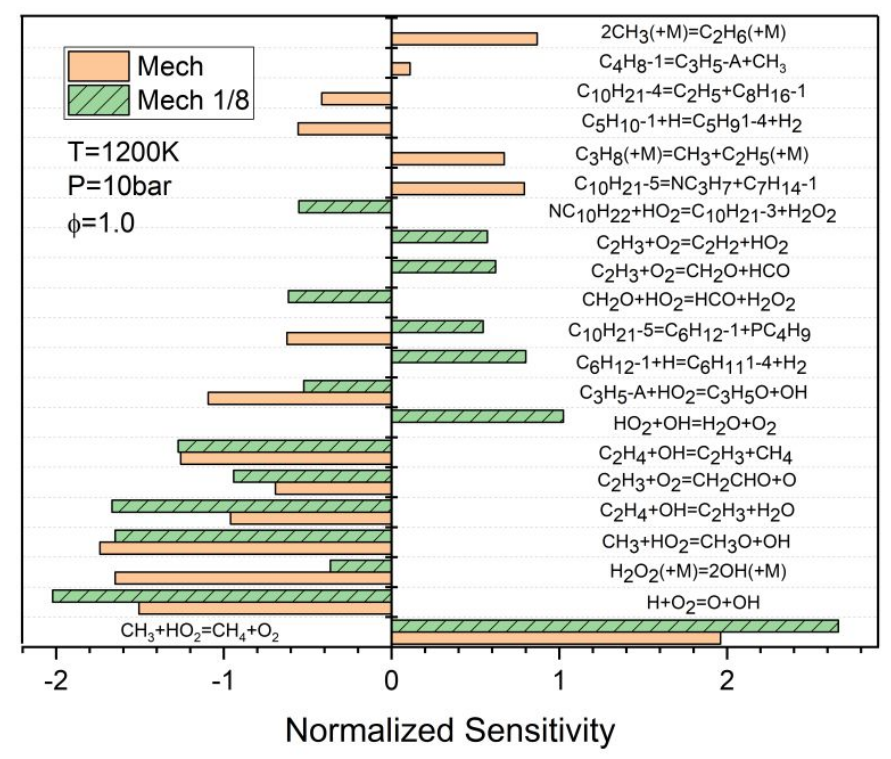

Figure S2. Brute force sensitivity analysis conducted at $1200 \mathrm{~K}$ and pressure of $10 \mathrm{bar}$ 


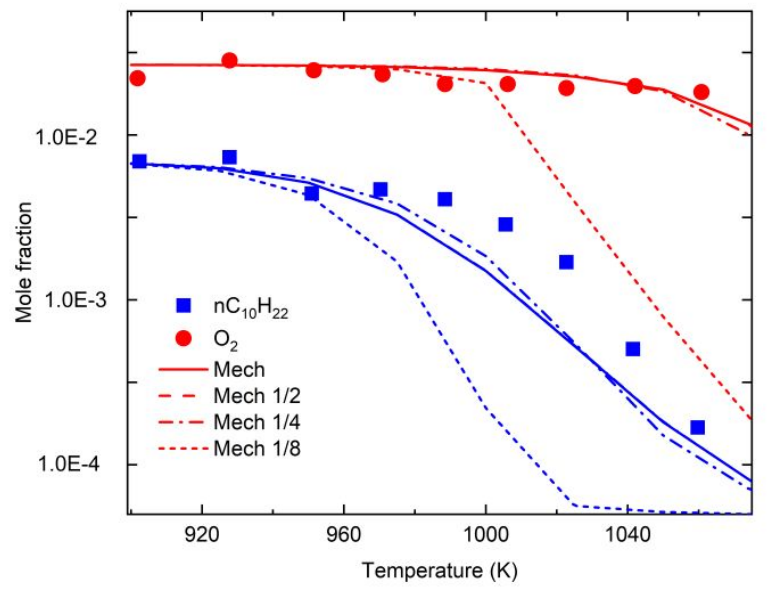

(a)

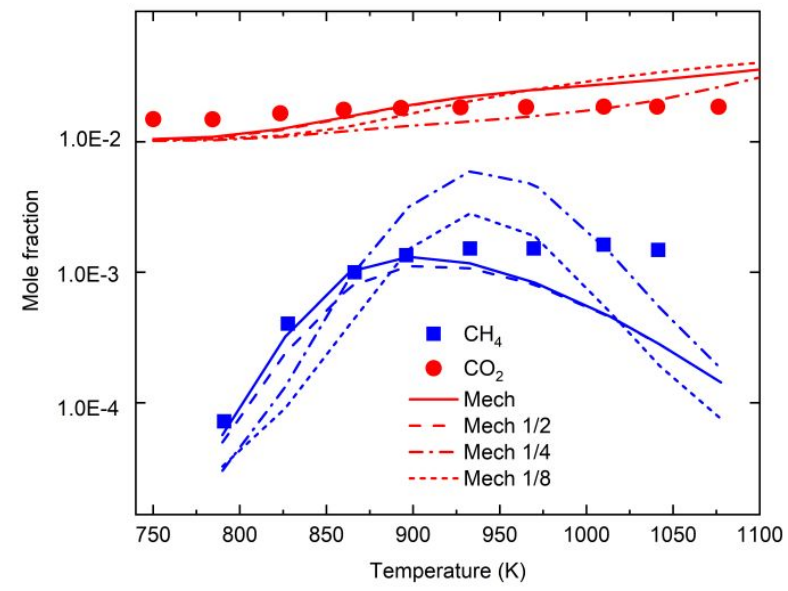

(b)

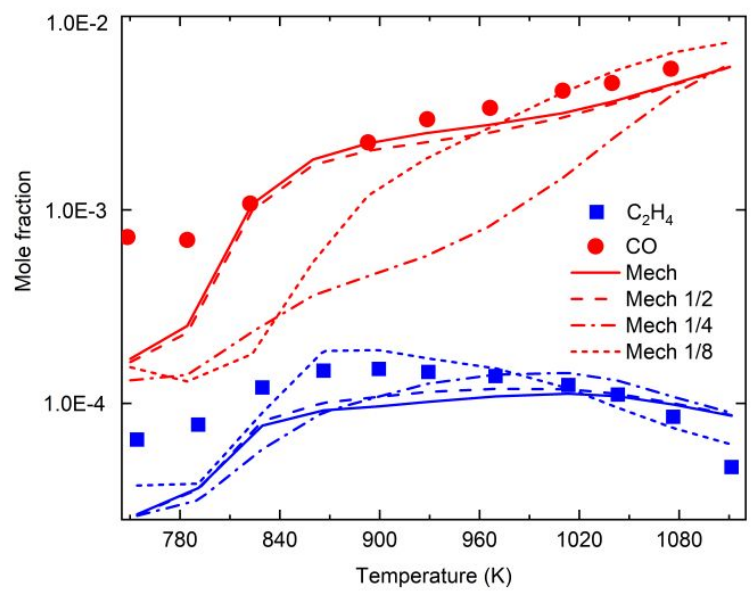

(c)

Figure S3. Mole fractions of species in a jet-stirred reactor (a) $\mathrm{nC}_{10} \mathrm{H}_{22}, \mathrm{O}_{2}$ at $700 \mathrm{ppm}$ of ndecane, the residence time of $0.07 \mathrm{~s}$ and a pressure of $1 \mathrm{~atm}$ (b) $\mathrm{CO}_{2}, \mathrm{CH}_{4}$ (c) $\mathrm{CO}, \mathrm{C}_{2} \mathrm{H}_{4}$ at 1000 ppm of n-decane, the residence time of $0.5 \mathrm{~s}$ and a pressure of 10atm. Experimental data are taken from 10,40 


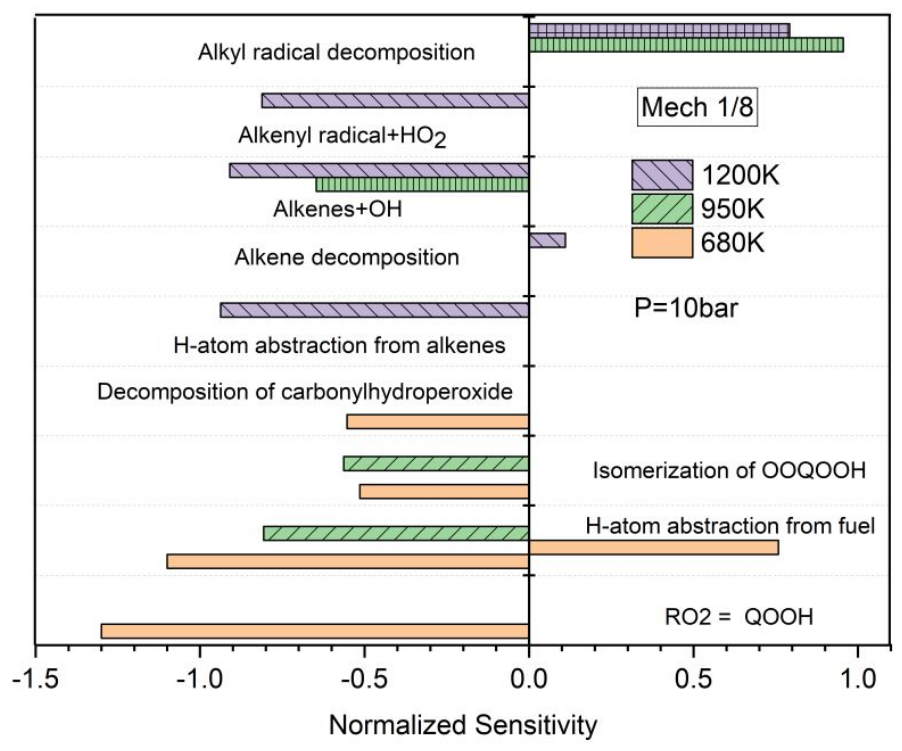

Figure S4. Brute force sensitivity analysis based on the reaction classes observed in the oneeighth reduced mechanism at $10 \mathrm{bar}$ and different temperature conditions.

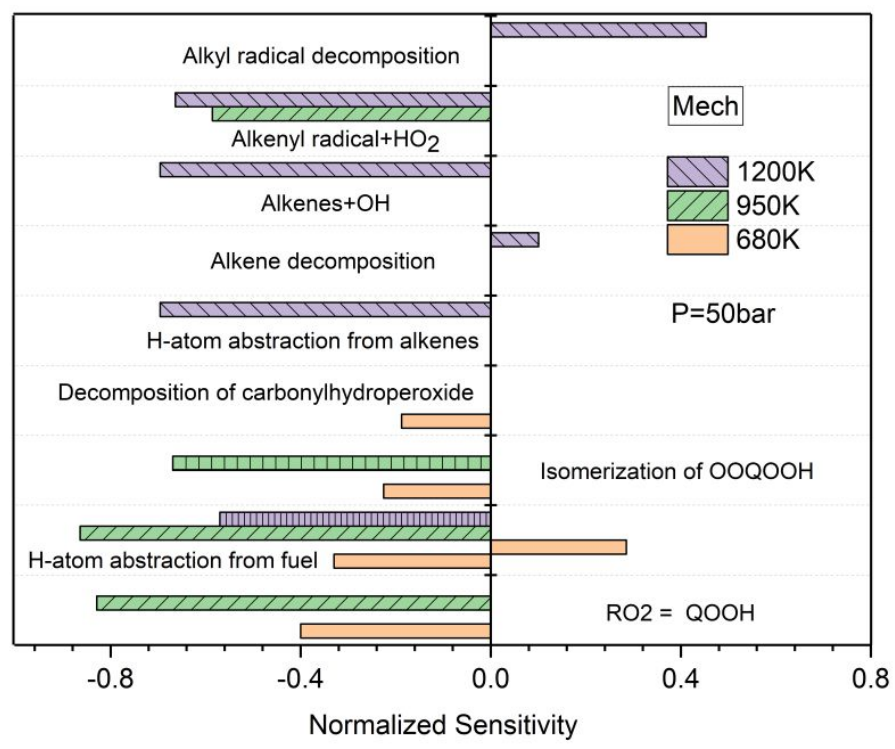

Figure S5. Brute force sensitivity analysis based on the reaction classes observed in the detailed mechanism at 50 bar and different temperature conditions. 


\section{Comparative performance evaluation of $1 / 8^{\text {th }}$ reduced mechanism}

Here we have present a comparison of our $1 / 8^{\text {th }}$ reduced mechanism with the skeletal/reduced mechanism of Chang et al. ${ }^{18}$ and Qiu et al. ${ }^{50}$ It must be noted here that this study is not focused on mechanism reduction and, therefore, the reduced mechanism has not been improved and is being presented in raw form.

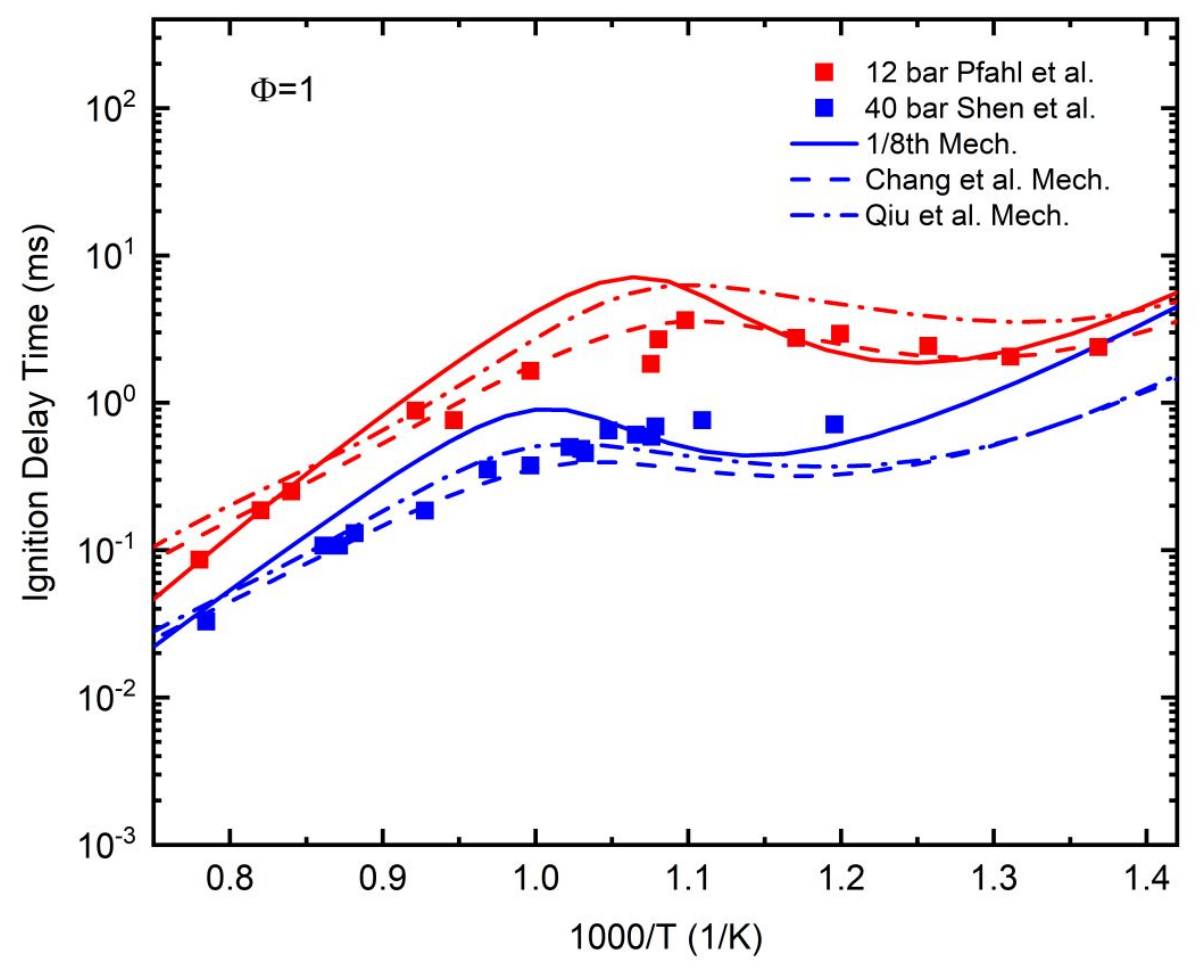

Figure S6. Comparison of n-decane ignition delays measured using current reduced mechanism and mechanism of Chang et al. ${ }^{18}$ and Qiu et al. ${ }^{50}$ 

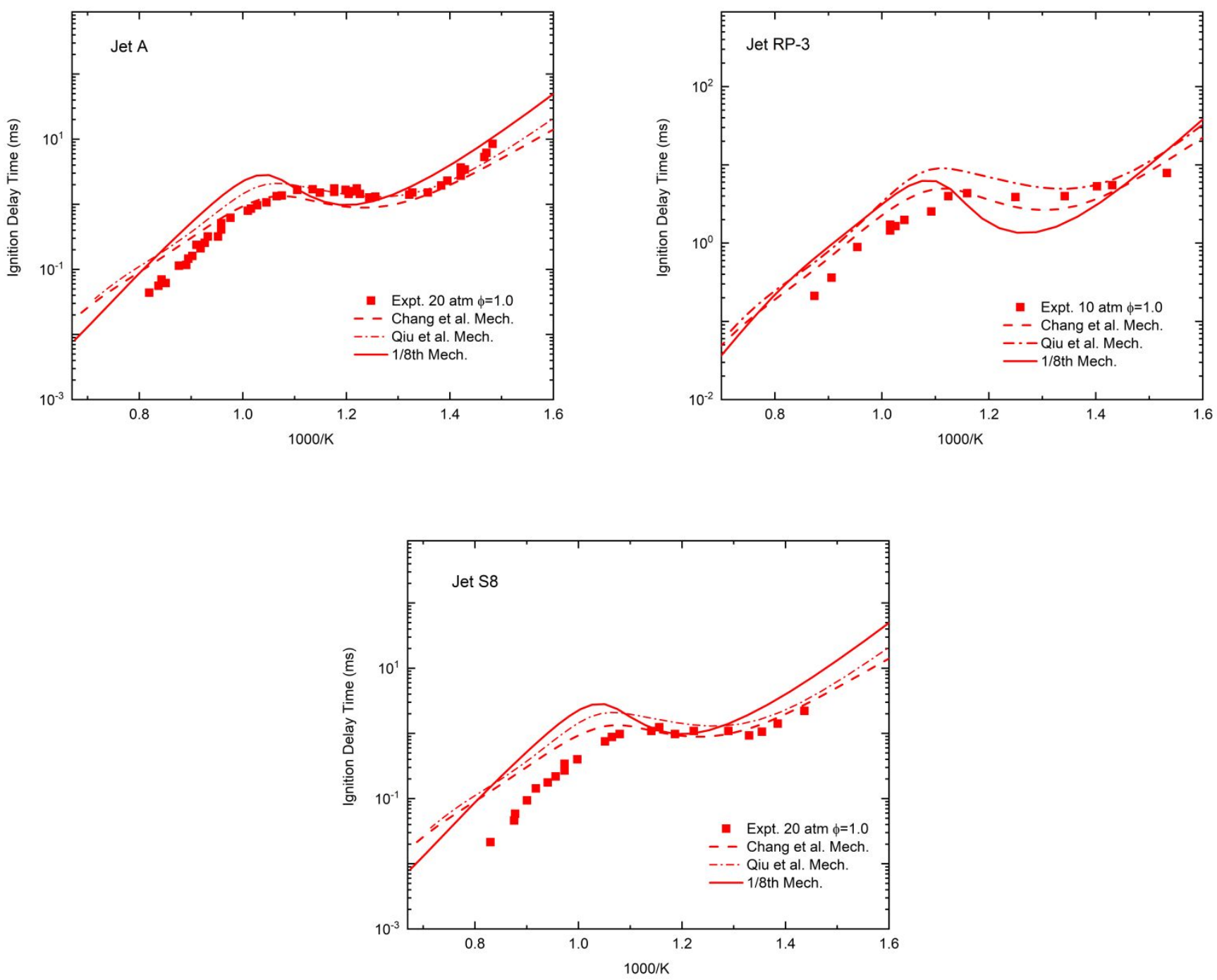

Figure S7. Comparison of ignition delays of Jet A, Jet RP-3, and Jet S8 fuels measured with current reduced mechanism and mechanism of Chang et al. ${ }^{18}$ and Qiu et al. ${ }^{50}$ 


\section{References}

(10) Dagaut, P.; Reuillon, M.; Cathonnet, Voisin, D. High pressure oxidation of normal decane and kerosene in dilute conditions from low to high temperature. J. Chim. Phys. 1995, 92, 47-76.

(18) Chang, Y. C.; Jia, M.; Liu, Y. D.; Li, Y. P.; Xie, M. Z. Development of a new skeletal mechanism for $\mathrm{n}$-decane oxidation under engine-relevant conditions based on a decoupling methodology. Combust. Flame 2013, 160 (8), 1315-1332.

(40) Douté, C.; Delfau, J.L.; Akrich, R.; Vovelle, C. Chemical structure of atmospheric pressure premixed n-decane and kerosene flames. Combust. Sci. Technol. 1995, 106 (4-6), 327-344. (50) Qiu, L.; Cheng, X.; Wang, X.; Li, Z.; Li, Y.; Wang, Z.; Wu, H. Development of a Reduced n-Decane/ $\alpha$-Methylnaphthalene/Polycyclic Aromatic Hydrocarbon Mechanism and Its Application for Combustion and Soot Prediction. Energy Fuels 2016, 30 (12), 10875-10885. 